\title{
A Facile Method of Preparing Highly Porous Polylactide Microfibers
}

DOI:

10.1002/app.45860

\section{Document Version}

Accepted author manuscript

Link to publication record in Manchester Research Explorer

\section{Citation for published version (APA):}

Liu, Q., Yang, Q., Zhou, Y., Zhao, M., Shen, Y., Zhou, F., Gong, R., \& Deng, B. (2018). A Facile Method of Preparing Highly Porous Polylactide Microfibers. Journal of Applied Polymer Science, 135(7), [45860]. https://doi.org/10.1002/app.45860

\section{Published in:}

Journal of Applied Polymer Science

\section{Citing this paper}

Please note that where the full-text provided on Manchester Research Explorer is the Author Accepted Manuscript or Proof version this may differ from the final Published version. If citing, it is advised that you check and use the publisher's definitive version.

\section{General rights}

Copyright and moral rights for the publications made accessible in the Research Explorer are retained by the authors and/or other copyright owners and it is a condition of accessing publications that users recognise and abide by the legal requirements associated with these rights.

\section{Takedown policy}

If you believe that this document breaches copyright please refer to the University of Manchester's Takedown Procedures [http://man.ac.uk/04Y6Bo] or contact uml.scholarlycommunications@manchester.ac.uk providing relevant details, so we can investigate your claim.

\section{OPEN ACCESS}




\section{A Facile Method of Preparing Highly Porous Polylactide Microfibers}

Qingsheng Liu ${ }^{1,2 *}$, Qibing Yang ${ }^{1}$, Yuqi Zhou ${ }^{1}$, Mingming Zhao ${ }^{1}$, Ying Shen ${ }^{1}$, Fenglei Zhou $^{2,3}$, R Hugh Gong ${ }^{2}$, Bingyao Deng ${ }^{1 *}$

${ }^{1}$ Key Laboratory of Eco-Textiles, Ministry of Education, Jiangnan University, Wuxi 214122,

China

2 The School of Materials, The University of Manchester, Manchester M13 9PL, United Kingdom

${ }^{3}$ Center for Imaging Sciences, The University of Manchester, Manchester M13 9PL, United Kingdom

*Corresponding author:

Qingsheng Liu, E-mail: lqs_1980@ @otmail.com, Tel: +86-13771087025, Fax: +86-051085912009

Bingyao Deng, E-mail: bydeng168@163.com, Tel: +86-13806185561, Fax: +86-051085912009 
ABSTRACT: Highly porous polylactide (PLA) microfibers with the diameter of about $14 \mu \mathrm{m}$ are prepared by melt-spinning and stretching core-sheath PLA fibers (CSF) and sequent treatment of ethyl acetate. The resultant pores are regular and elliptical. The average values of length of major axis and minor axis of elliptical pores are around 1 and $0.5 \mu \mathrm{m}$, respectively. This new and facile method can prepare porous PLA fibers on industrial scale, and nearly overcome all the shortcomings of melt-spinning and stretching method. In addition, highly porous structure in partially oriented PLLA yarn (POY) can be also formed by treating POY using ethyl acetate. The obtained pores is irregular. In addition, the formation mechanism of pore structure in CSF is different with the one in POY. The former is the separation of rownucleated lamellae induced by stretching while the latter is swelling and subsequent solventinduced crystallization.

KEYWORDS: core-sheath fiber; porous fibers; polylactide; melt-spinning, drawing; ethyl acetate 

been widely studied as a raw material of synthetic fibers. ${ }^{4}$ It is well known that porous structures enable fibers to have high specific surface area and high surface activity, ${ }^{5}$ which are beneficial for a number of special fields, such as controlled drug release, tissue engineering, wound dressings, catalysis, filtration, absorption and so on. ${ }^{5,6}$ Therefore, the study on porous PLA fibers is an important and popular subject. A few methods of preparing highly porous PLA fibers have been previously reported. Sun et al. $^{5}$ prepared porous PLA fibers by electrospinning PLA in the mixed solvents of N,N-dimethylformamide (DMF) and chloroform $\left(\mathrm{CHCl}_{3}\right)$. Bognitzki et al. ${ }^{7}$ produced porous PLLA electrospun fibers by using methylene chloride $\left(\mathrm{CH}_{2} \mathrm{Cl}_{2}\right)$ as solvent. Yu et al. ${ }^{8}$ prepared PLLA ultrafine multi-porous hollow fibers by electrospinning with $\mathrm{CH}_{2} \mathrm{Cl}_{2}$ as solvent. Valipouri et al. ${ }^{9}$ fabricated porous PLA electrospun fibers using $\mathrm{CHCl}_{3}$ as solvent. Lee et al. ${ }^{10}$ prepared porous PLA/MMT composite fibers in the electrospinning process using $\mathrm{CHCl}_{3}$ as solvent. The mechanism behind the formation of porous PLA fibers was a rapid phase separation induced by the evaporation of the volatile solvents. Qi et $\mathrm{al}^{11}$ produced porous PLA electrospun fibers using alcohol as nonsolvent and $\mathrm{CH}_{2} \mathrm{Cl}_{2}$ as solvent. Zhang et al. ${ }^{12}$ fabricated porous PLLA electrospun fiber using DMF and $\mathrm{CH}_{2} \mathrm{Cl}_{2}$ as the mixed solvent. Here, the mechanism of forming porous PLA fibers was nonsolvent-induced phase separations (NIPS). In addition, Tian et al. ${ }^{13}$ prepared porous PLA fibers by immersing the electrospun PLA fibers in methanol and acetone at desired temperatures for a certain time period, respectively, followed by vacuum drying at room temperature to remove the residual solvents. The formation of porous structure was mainly due to swelling and subsequent solvent-induced crystallization in the electrospun PLA fibers. However, up to now, porous PLA fibers are fabricated mainly by electrospinning method which is limited by low throughput. 
The method of melt-spinning and cold-stretching (MSCS) is considered to be a valuable and simple way to produce porous hollow fiber membranes ${ }^{14}$. This method, including mainly three steps, has been used widely to prepare polypropylene (PP), polyethylene (PE) and polyvinylidene fluoride (PVDF) porous hollow fiber membranes. ${ }^{14-21}$ The first step is melt-spinning, during which row-nucleated lamellar structure in fibers can be created by stress-induced crystallization effects. ${ }^{15}$ The second step is an annealing process, which can enhance the perfection of crystalline structure..$^{15}$ The third step is stretching, which is carried out in two stages consisting of cold stretching followed by hot stretching. Cold stretching is used to produce microcrazes uniformly in amorphous regions between lamellae. These microcrazed amorphous regions are finally transformed into an open slit-shaped pore by hot stretching. ${ }^{15}$ This method is clean and economical, and the obtained porous fibers have high mechanical strength. ${ }^{14}$ The formation of row-nucleated lamellar structure is prerequisite for producing porous structure by stretching. When high stress is applied, row-nucleated lamellar structures can be readily created by stress-induced crystallization effects during the melt spinning. ${ }^{15}$ However, it is well known that the crystallization of PLA is very slow. ${ }^{22}$ So it is difficult to develop significant crystallinity and row-nucleated lamellar structure during melt-spinning. In addition, up to now, the diameters of porous hollow fibers prepared by MSCS are more than $200 \mu \mathrm{m} \cdot{ }^{14-16,19,20}$ Formation of pores with the diameter of about $1 \mu \mathrm{m}$ did not affect the process of forming pores by stretching porous hollow fiber with more than $200 \mu \mathrm{m}$. However, generally speaking, the diameter of common synthetic fiber is less than $20 \mu \mathrm{m} .{ }^{[23]}$ The pores with about $1 \mu \mathrm{m}$ would make the common synthetic fibers break easily during cold and hot stretching so that it is difficult to prepare porous PLA fibers with less than $20 \mu \mathrm{m}$. In addition, although porous fibers manufactured by this method 
have good mechanical strength along the machine direction, the low tensile strength along the transverse direction may result in splitting problems. ${ }^{24}$

Here, a new and facile method that potentially can prepare porous PLA fibers on industrial scale is put forward. In this work, core-sheath PLA fiber (named CSF) was designed. The core and sheath materials were poly(L-lactide) (PLLA) and polylactide with D-latide of about 10 mol\% (PLA90), respectively. The viscosity of PLLA was higher than that of PLA90. ${ }^{25}$ During melt-spinning, the stress would impose mainly on the PLLA in the core layer so that the tensile stress imposed on PLLA in the core layer of core-sheath PLA fiber was higher than the one imposed on common PLLA fiber. High stress would induce the formation of PLLA core layers with row-nucleated lamellar structure and relatively high crystallinity. The pore structure in PLLA core layers would form by sequent two-step stretching. However, no pores could be observed in sheath layers. PLA90 with low crystallinity and PLLA with high crystallinity have different solubility in ethyl acetate. Ethyl acetate could dissolve PLA90 partly to present the pores in PLLA core layers. In addition, the PLA90 sheath layers could protect the porous PLLA fiber in core layers from breaking during cold and hot stretching, and splitting during using.

\section{EXPERIMENTAL}

Material Preparation. The core-sheath PLA fibers (CSF), partially oriented PLLA yarn (POY) and draw-textured PLLA yarn (DTY) were manufactured by Hengtian Changjiang Biological Materials Co. Ltd (China). The core and sheath materials in CSF were poly(Llactide) (PLLA) and polylactide with D-latide of about 10 mol\% (PLA90), respectively. The weight ratio of core and sheath layers was 65:35. CSFs were prepared by the following process: melt spinning $\rightarrow$ two-step drawing $\rightarrow$ crimping $\rightarrow$ setting $\rightarrow$ cutting. DTY was prepared by drawing and twisting/untwisting simultaneously POY. 
Firstly, CSF, POY and DTY were immersed in ethyl acetate for different time (5, 10, 20, 30, DTY were taken out from ethyl acetate and dried naturally.

Differential Scanning Calorimetry. The crystallization behaviors and melting behaviors of samples were characterized by differential scanning calorimetry (DSC) that used a DSC Q200 (TA Instruments ${ }^{\circledR}$, Inc.). Nitrogen was used at a flow rate of $50 \mathrm{~mL} / \mathrm{min}$. The instrument was calibrated with $\mathrm{In}$ and $\mathrm{Pb}$. The weight of the samples was in the range of $4 \sim 6 \mathrm{mg}$. Each sample was heated from 0 to $200^{\circ} \mathrm{C}$ at $10^{\circ} \mathrm{C} / \mathrm{min}$.

Scanning Electron Microscope. Scanning electron microscope (SEM) measurements of longitudinal surface of fibers, cross-section of cryogenically fractured samples in liquid nitrogen, and cross-section of tensile-fractured samples were carried out by a Model SU1510 scanning electron microscope (Hitachi, Japan). The samples were sputtered with gold before the SEM observation.

Surface Area and Porosity Analysis. The Brunauer-Emmett-Teller (BET) surface area, pore volume and pore width of samples were characterized by nitrogen adsorption and desorption using a surface area and porosity analyzer (TriStar II 3020, Micromeritics, USA). Prior to analysis, fibers were degassed for at least $6 \mathrm{~h}$ at $45^{\circ} \mathrm{C}$.

\section{RESULTS AND DISCUSSION}

Thermal behaviors. The thermal behaviors of POY, DTY and CSF were studied by DSC. The DSC curves are shown in Figure 1(a). In the low temperature region from 42.4 to $90.0^{\circ} \mathrm{C}$, the glass transition temperature $\left(T_{g}\right)$ and cold-crystallization temperature $\left(T_{c c}\right)$ of POY overlap partly. The melting point $\left(T_{m}\right)$ of POY is $174.0^{\circ} \mathrm{C}$. The corresponding melting enthalpy $\left(\Delta H_{m}\right)$ is $52.1 \mathrm{~J} / \mathrm{g}$. The $T_{m}$ of DTY appears at $168.4^{\circ} \mathrm{C}$. The corresponding $\Delta H_{m}$ is $58.2 \mathrm{~J} / \mathrm{g}$. It can be found that $\Delta H_{m}$ of DTY is higher than that of POY and a large cold-crystallization peak in the DSC curve of POY appears, indicating that the crystallinity of POY is much lower than that 
of DTY. In the DSC curve of CSF, the two melting peaks appear at $132.8^{\circ} \mathrm{C}(6.6 \mathrm{~J} / \mathrm{g})$ and $175.5^{\circ} \mathrm{C}(38.3 \mathrm{~J} / \mathrm{g})$, attributed to sheath and core layers, respectively. The $\Delta H_{m}$ of core layer is 5.8 times of that of the sheath layer while the weight fraction of core layer only is 1.9 times of that of the sheath layer, which shows that the sheath layer crystallizes more difficultly than core layer because of the existence of high D-LA content in the molecular chain of sheath layer.

The effect of ethyl acetate on CSF. The surface morphologies of CSF were observed by SEM, which are shown in Figure 1(b) and (c). Figure 1(b) and (c) illustrate that transverse stripe in CSF with the diameter of about $14 \mu \mathrm{m}$ exists, and no pores can be observed. However, when the assembly of CSF was hot-pressed into composite at the temperature between $T_{m}$ of sheath layer and that of core layer, the sheath layers PLA90 melted to matrix while the core layers as reinforcements did not melt. Figure 1(d) and (e) show the SEM micrographs of tensile-fractured and cryogenically fractured cross-section of the composite, respectively. Highly porous structures can be observed in the longitudinal direction and cross-section of PLLA core layers. This indicates that pores have formed in the PLLA core layers by melting spinning and stretching. However, the pores are covered by sheath layers so that the pores in core layers can not be observed. The pores will appear as soon as sheath layers are removed.
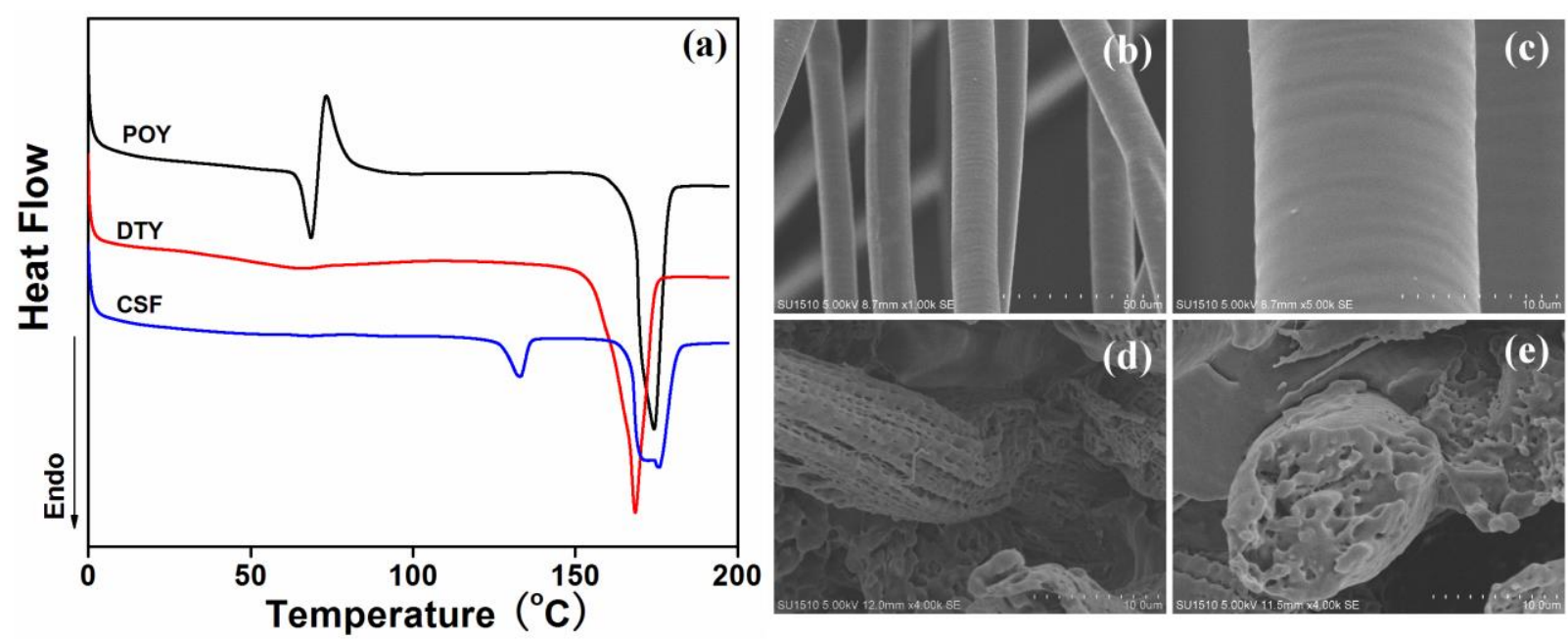

Figure 1 (a): DSC curves of POY, DTY, and CSF; (b) and (c): SEM micrographs of 
surface morphology of orignal CSF; SEM micrographs of tensile-fractured (d) and cryogenically fractured (e) cross-section of the composite prepared by CSFs.

In order to make highly porous structure in core layers appear, CSFs was treated by the solvent of ethyl acetate at room temperature. SEM micrographs of surface morphology of highly porous PLA fibers are shown in Figure 2. Figure 2 illustrates that CSFs treated for 5 min and 60 min have highly porous structures. However, the distribution of pores in different CSFs treated for $5 \mathrm{~min}$ is not uniform while that of pores in different CSFs treated for $60 \mathrm{~min}$ are relatively uniform. In addition, it can been also found from Figure S1 (Supporting information) that for CSF treated for $5 \mathrm{~min}$, the distribution of pores in the same fiber is uneven. However, for the CSF treated for 60min, the pores distribute evenly in the different parts of the same fiber. The shape of pores is elliptical. The morphology is similar to that of the pores formed by the evaporation of the volatile solvents during electrospinning ${ }^{9}$. However, the morphology is different with that of the pores in micro-porous fiber membranes prepared by the melt-spinning and cold stretching method (MSCS). The pores formed by MSCS are slit-like, and the separated lamellae are connected by microfibrillar bridges. ${ }^{21}$ Figure S1 also shows that the pores can distribute evenly in different fibers or in the different parts of one fiber when the immersing time was $10 \mathrm{~min}$. When the immersing time is above $10 \mathrm{~min}$, with the increase of immersing time, the pore structure and distribution remain almost unchanged (See Figure S1). The average values of length of major axis and minor axis of elliptical pores are around 1 and $0.5 \mu \mathrm{m}$, respectively, which is characterized by SEM. In addition, the data obtained by BET measurements (Figure 3) are listed in Table 1. Table 1 shows that BET surface area and cumulative volume of pores of CSF treated by ethyl acetate for 30 and $60 \mathrm{~min}$ are much larger than those of original CSF. However, BET surface area and cumulative volume of pores of CSF treated by ethyl acetate for 30min is close to those of CSF treated by ethyl acetate for $60 \mathrm{~min}$, which further reveals that with the prolongation of treatment time, the 
structure of pores in CSF does not almost change. The BJH adsorption average pore width of

pores of CSF treated by ethyl acetate for 30 and $60 \mathrm{~min}$ is 420 and $427 \mathrm{~nm}$, respectively.
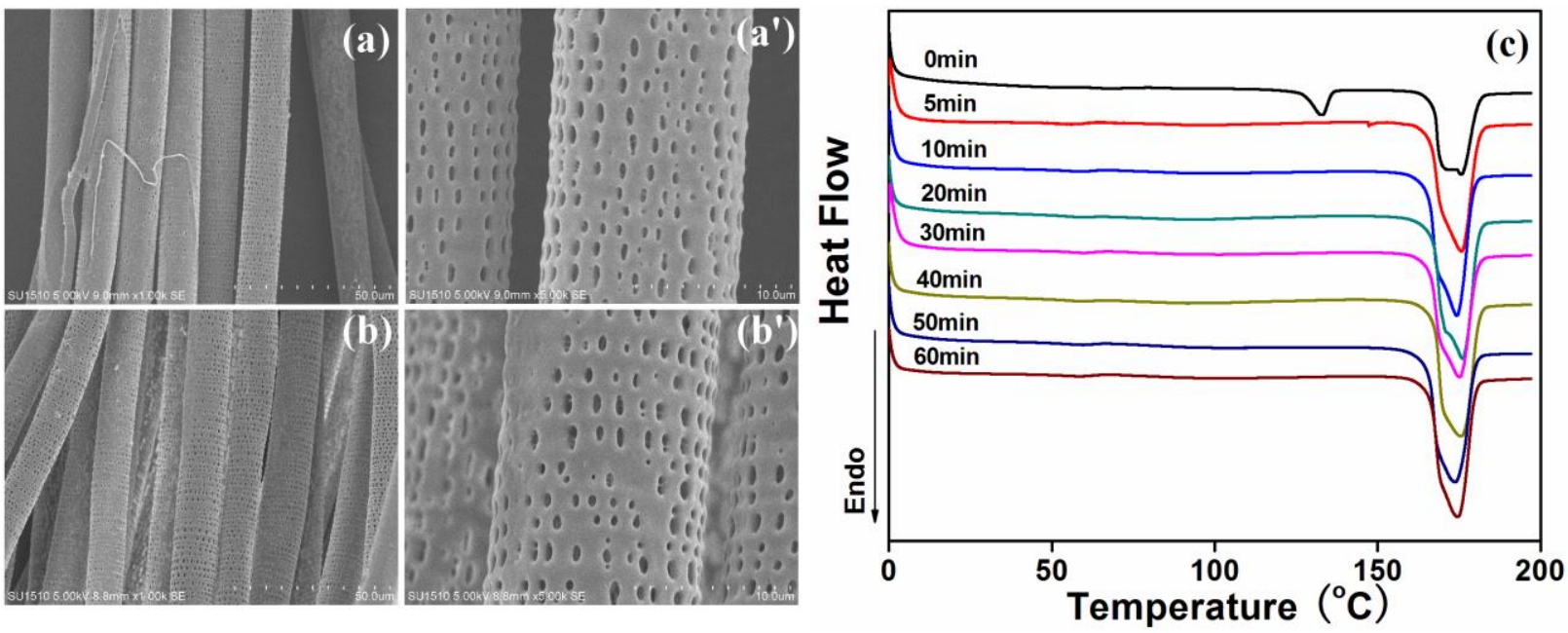

Figure 2 SEM micrographs of surface morphology of CSF treated by ethyl acetate for $5 \mathrm{~min}(\mathrm{a}$ and a') and 60min (b and b'), respectively; (c) : The heating DSC curves $\left(10^{\circ} \mathrm{C} / \mathrm{min}\right)$ of CSF treated by ethyl acetate for different time.

The weight loss of CSF treated by ethyl acetate for 5, 10, 20, 30, 40, 50 and $60 \mathrm{~min}$ is $33.5,34.8,35.0,35.5,35.5,35.0$ and $35.5 \%$, respectively. This shows that when the treating time is above $10 \mathrm{~min}$, the weight loss is nearly constant, which is consistent with the result that the morphology of those samples treated above 10min does not change. In addition, the weight fraction of sheath layer in original CSF is 35\%, which is close to weight loss of CSF treated by ethyl acetate for more than $10 \mathrm{~min}$. Figure 1 and 2 show that the diameter of original CSF is nearly equal to that of the treated CSF, which shows that the sheath layer is dissolved partly. And only the sheath layers in the location of forming pores are dissolved. Therefore, the weight loss is attributed partly to the core layers, which illustrates that ethyl acetate also dissolves partly core layers of CSF. Figure 2(c) illustrates the DSC curves of CSF treated by ethyl acetate for different time. All the treated CSFs exhibit a single melting peak near $175^{\circ} \mathrm{C}$, which is attributed to the melting of core layers. The melting peak of sheath layers is not 
observed, which reveals that the crystals in sheath layers can also be destroyed by ethyl min was $38.4,56.5,60.1,61.0,54.5,60.4,60.2$ and $59.7 \mathrm{~J} / \mathrm{g}$, respectively. The $\Delta H_{m}$ of original CSF is much lower than that of the treated CSFs mainly because the dissolution of sheath layers results in the increase of relative content of core layers of CSFs. It is assumed that weight loss of treated CSF is attributed to dissolution of sheath layers and amorphous part of core layers, the $\Delta H_{m}$ of CSF treated by ethyl acetate for $5,10,20,30$, 40, 50 and 60 min can be calculated according to the weight loss of treated CSFs and $\Delta H_{m}$ of original CSF. The corresponding $\Delta H_{m}$ is $57.7,58.9,59.1,59.1,58.9$ and $59.1 \mathrm{~J} / \mathrm{g}$, respectively, which is close to the experimental values obtained by DSC. Therefore, it can be concluded that ethyl acetate does not noticeably affect the crystalline part of core layer (PLLA) of CSF. In addition, it is known from the above results that ethyl acetate can dissolve PLA90 in sheath layers covering the pore in core layers while ethyl acetate can only swell the PLA90 in sheath layers covering PLLA lamellae in core layers, probably due to strong adhesion between PLA90 and PLLA. The remaining sheath layer also can keep the high porous layers from splitting during using.

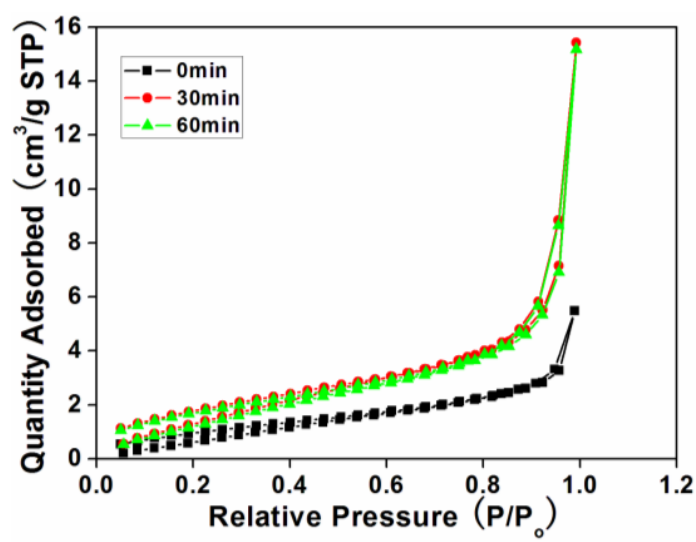

Figure 3 Nitrogen adsorption-desorption isotherms of original CSF and CSF treated by ethyl acetate at room temperature for 30 and $60 \mathrm{~min}$ 
Table 1 BET surface area and cumulative volume of pores of original CSF and CSF

\begin{tabular}{cccc}
\hline \multirow{2}{*}{ Treatment time } & BET surface area $\left(\mathrm{m}^{2} / \mathrm{g}\right)$ & & \multicolumn{2}{c}{ Cumulative volume of pores $\left(\mathrm{cm}^{3} / \mathrm{g}\right)$} \\
\cline { 3 - 4 } & & & \\
\hline 0min & 4.2440 & 0.003411 & 0.003453 \\
30min & 6.5789 & 0.006386 & 0.006757 \\
60min & & & \\
& 6.1544 & 0.006244 & 0.006537 \\
& & & \\
\hline
\end{tabular}

It can concluded from above analysis that the construction of the core-sheath structure nearly can solve all problems of preparing highly porous PLA fibers using meltspinning and stretching method. Firstly, enhancing the tensile stress imposing on PLLA in core layers during melt spinning was beneficial to formation of row-nucleated lamellar structure. Secondly, sheath layers protected the porous PLLA fibers in core layers from breaking during stretching. Thirdly, remaining sheath layers could stop porous PLA fibers from splitting during using. Moreover, during preparing porous PLA fibers, annealing (In the classical melt-spinning and stretching method, the annealing time is more than 10min.) ahead of cold-stretching was not used, which saved the processing time. It is concluded that this is an efficient method to prepare porous PLA fibers with relatively small diameter on a large scale.

The effect of ethyl acetate on POY and DTY. To prove that this kind of highly porous structure only could be created in the designed core-sheath PLA fibers, the POY and DTY of PLLA were also treated by ethyl acetate. Figure 4 shows the SEM micrographs of original POY and the POY treated by ethyl acetate for $60 \mathrm{~min}$. The 
surface of original POY is nearly smooth while irregular porous structure appears in pores exist, no weight loss occurs with any treatment time. In addition, the DSC curves in Figure 4(c) show that the cold-crystallization peak of treated POY disappears while the $\Delta H_{m}(52.1 \mathrm{~J} / \mathrm{g}$ for original POY, 50.7J/g for POY treated for $5 \mathrm{~min}, 51.0 \mathrm{~J} / \mathrm{g}$ for POY treated for $10 \mathrm{~min}, 51.0 \mathrm{~J} / \mathrm{g}$ for POY treated for $20 \mathrm{~min}, 46.0 \mathrm{~J} / \mathrm{g}$ for POY treated for $30 \mathrm{~min}, 47.6 \mathrm{~J} / \mathrm{g}$ for POY treated for 40min, 49.5J/g for POY treated for 50min, and 51.3J/g for POY treated for 60min) remains almost unchanged. The experimental results illustrate that the formation of irregular pores in POY is attributed to swelling and subsequent solvent-induced crystallization. The formation mechanism is accorded with the one proposed by Tian et al. ${ }^{[13]}$. Figure 5 shows the SEM micrographs of original DTY and the DTY treated by ethyl acetate for $60 \mathrm{~min}$. It can be seen that the surface of the original DTY is relatively smooth while a small quantity of longitudinal grooves with the average width of about $1 \mu \mathrm{m}$ appear on the surface of some DTY treated by ethyl acetate for $60 \mathrm{~min}$. It can be calculated from the DSC curves in Figure 5(c) show that the $\Delta H_{m}$ s of original DTY, DTY treated for 5min, DTY treated for $10 \mathrm{~min}$, DTY treated for $20 \mathrm{~min}$, DTY treated for $30 \mathrm{~min}$, DTY treated for 40min, DTY treated for 50min, and DTY treated for 60min are 58.8, 58.9, $58.9,59.0,59.6,60.7,61.5$, and $62.1 \mathrm{~J} / \mathrm{g}$, respectively, and the corresponding crystallinity is $62.8,62.9,62.9,63.0,63.7,64.9,65.7$, and $66.3 \%$, respectively. The crystallinity of the treated DTY is a bit higher than that of the original DTY. With the increase of the prolongation of the treatment time, the crystallinity of the treated DTY increases. This shows that ethyl acetate affects the amorphous part of DTY. However, the effect of ethyl acetate on the amorphous part of DTY is small because the number of grooves and the change of crystallinity are small. The grooves form, probably due to the damage of amorphous part. 

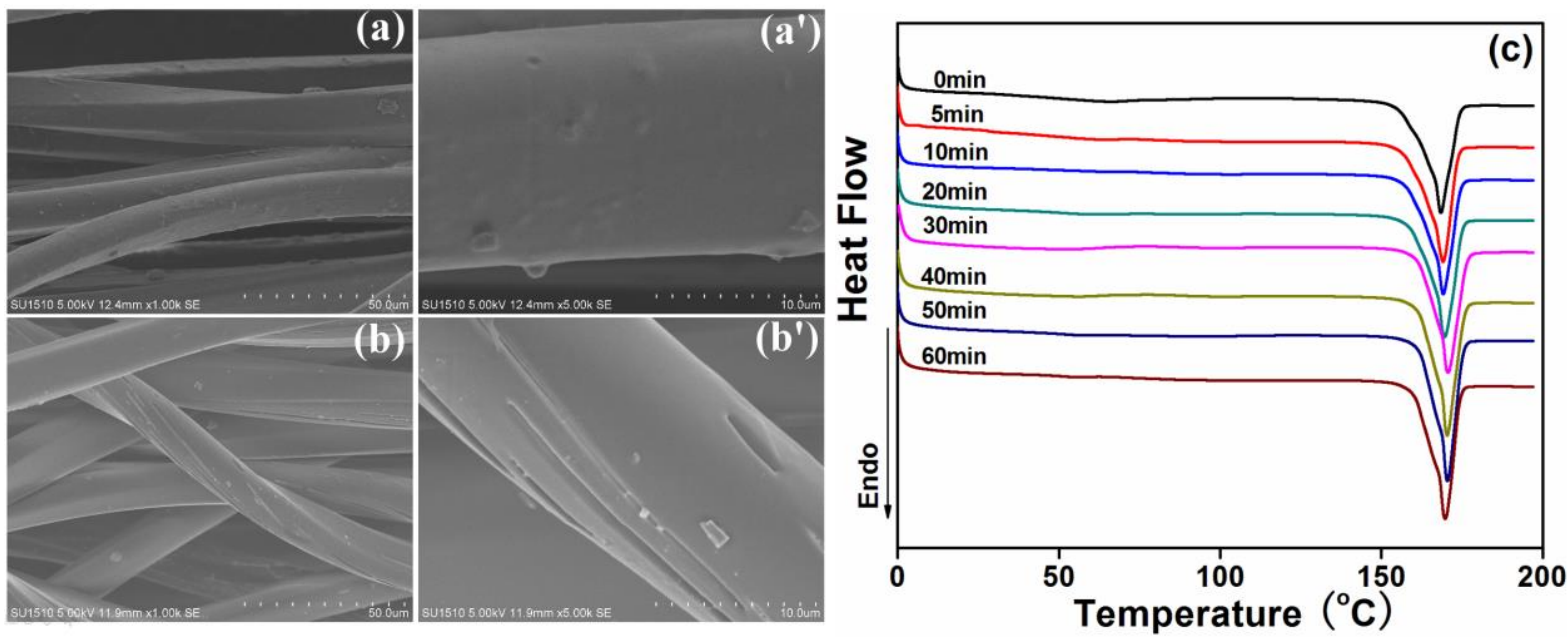

Figure 5 SEM micrographs of surface morphology of original DTY (a and a') and

DTY treated by ethyl acetate for 60min (b and b'), respectively; (c): The heating DSC curves $\left(10^{\circ} \mathrm{C} / \mathrm{min}\right)$ of DTY treated by ethyl acetate for different time.

\section{CONCLUSIONS}

PLA fibers with core-sheath structure first were prepared and then treated by ethyl acetate to obtain highly porous PLA microfibers with small diameter. The resultant pores on core-sheath fibers are regular and elliptical. The formation mechanism is the separation of row-nucleated lamellae by stretching, which were obtained by melt-spinning. This new and facile method can prepare porous PLA fibers on an industrial scale, and overcomes nearly all the limitations 
of melt-spinning and stretching method. In addition, highly porous structure could be also formed in POY, due to swelling and subsequent solvent-induced crystallization of POY with low crystallinity. However, the pore structures in POY were found to be irregular. A small quantity of longitudinal grooves with the average width of about $1 \mu \mathrm{m}$ appeared on the surface of some DTY treated by ethyl acetate.

\section{ACKNOWLEDGEMENTS}

This research was supported by the National Natural Science Foundation of China (51403084), the Jiangsu Overseas Research Training Program for University Prominent Young and Middle-Aged Teachers and Presidents, the Natural Science Foundation of Jiangsu Province (BK20130142), and the Priority Academic Program Development of Jiangsu Higher Education Institutions. 


\section{REFERENCES}

1. Liu, Q. S.; Wu, C.; Zhang, H. X.; Deng, B. Y. J. Appl. Polym. Sci. 2015, 132, 42689.

2. Liu, Q. S.; Jiang, J. Z.; Zhang, H. X.; Wang, J. C.; Li, X. M.; Li, Y. H.; Deng, B. Y. Polym.-Plast. Technol. Eng. 2014, 53, 1590-1597.

3. Liu, Q. S.; Zhang H. X.; Zhu, M. F.; Dong, Z.; Wu, C.; Jiang, J. Z.; Li, X. M.; Luo, F.;

Gao, Y. X.; Deng, B. Y.; Zhang, Y.; Xing, J.; Wang, H. F. Fiber. Polym. 2013, 14, 16881698.

4. Liu, Q. S.; Sun, Y. Y.; Xia, S. N.; Zhang, H. X.; Tao, X. L.; Liu, Y. H.; Deng, B. Y. Text. Res. J. 2016, 86, 948-959.

5. Sun Z. Y.;Fan, C. X.; Tang, X. P.; Zhao, J. H.; Song, Y. H.; Shao, Z. B.; Xu, L. Appl. Surf. Sci. 2016, 387, 828-838.

6. Wang, Y. Z.; Wang, B. C.; Wang, G. X.; Yin, T. Y.; Yu, Q. S. Polym. Bull. 2009, 63, 259-265.

7. Bognitzki, M.; Czado, W.; Frese, T.; Schaper, A.; Hellwig, M.; Steinhart, M.; Greiner, A.; Wendorff, J. H. Adv. Mater. 2001, 13, 70-72.

8. Yu, Q. Z.; Qin, Y. M. eXPRESS Polym. Lett. 2013, 7, 55-62.

9. Valipouri, A.; Gharehaghaji, A. A.; Ravandi, S. A. H.; Dabirian, F. J. Ind. Text. 2015, 44, 899-911.

10. Lee, Y. H.; Lee, J. H.; An, I.-G.; Kim, C.; Lee, D. S.; Lee, Y. K.; Nam, J.-D.

Biomaterials 2005, 26, 3165-3172.

11. Qi, Z. H.; Yu, H.; Chen, Y. M.; Zhu, M. F. Mater. Lett. 2009, 63,415-418.

12. Zhang, K.; Wang, X. F.; Jing, D. Z.; Yang, Y.; Zhu, M. F. Biomed. Mater. 2009, 4, 035004.

13. Tian, R. P.; Zhang, P.; Lv, R. H.; Na, B.; Liu, Q. X.; Ju, Y. H. Rsc Adv. 2015, 5, $37539-37544$. 
14. Han, S. W.; Woo, S. M.; Kim, D. J.; Park, O. O.; Nam, S. Y. Macromol. Res. 2014, 22, 618-623.

15. Kim, J. H.; Kim, S. S.; Park, M. S.; Jang, M. S. J. Memb. Sci. 2008, 318, 201-209.

16. Kim, J.-J.; Jang, T.-S.; Kwon, Y.-D.; Kim, U. Y.; Kim, S. S. J. Memb. Sci. 1994, 93, 209215.

17. Lee, S.-Y.; Park, S.-Y.; Song, H.-S. Polymer 2006, 47, 3540-3547.

18. Kim, T. H.; Jee, K. Y.; Lee, Y. T. Macromol. Res. 2015, 23, 592-600.

19. Liu, X.-D.; Ni, L.; Zhang, Y.-F.; Liu, Z.; Feng, X.-S.; Ji, L. Adv. Mater. Res. 2012, 418420, 26-29.

20. Xi, Z.-Y.; Xu, Y.-Y; Zhu, L.-P.; Du, C.-H.; Zhu, B.-K. Polym. Adv. Technol. 2008, 19, 1616-1622.

21. Shao, H. J.; Wei, F. J.; Wu, B.; Zhang, K. Z.; Yao, Y.; Liang, S. M.; Qin, S. H. RSC Adv. 2016, 6, 4271-4279.

22. Battegazzore, D.; Bocchini, S.; Frache, A. eXPRESS Polym. Lett. 2011, 10, 849-858.

23. Frank, K. K. in Natural Fibers, Plastics and Composites, ed. Frederick T. W.;

Norman, W. Kluwer Academic Publishers, Massachusetts, USA, 2004, p29.

24. Lin, K.-Y.; Xanthos, M.; Sirkar, K. K. J. Memb. Sci. 2009, 330, 267-278.

25. Ahmed, J.; Varshney, S. K. Int. J. Food Prop. 2011, 14, 37-58. 

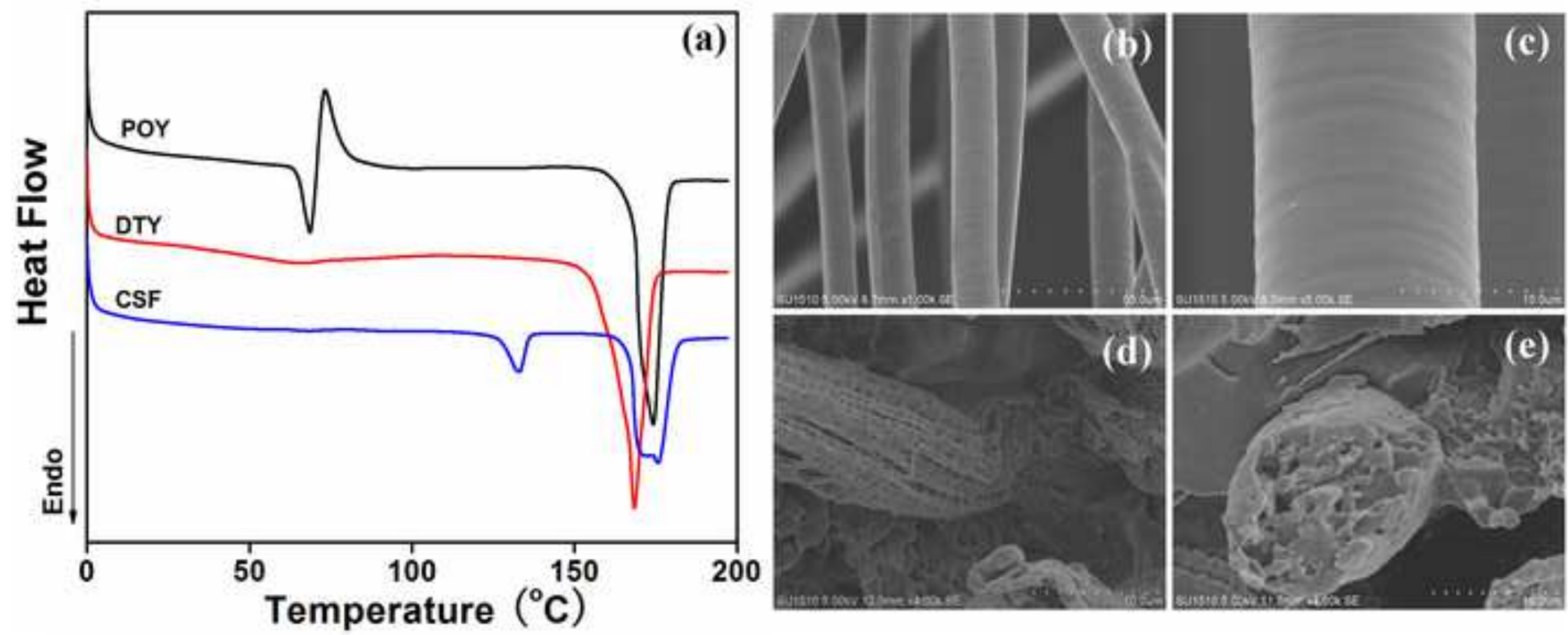

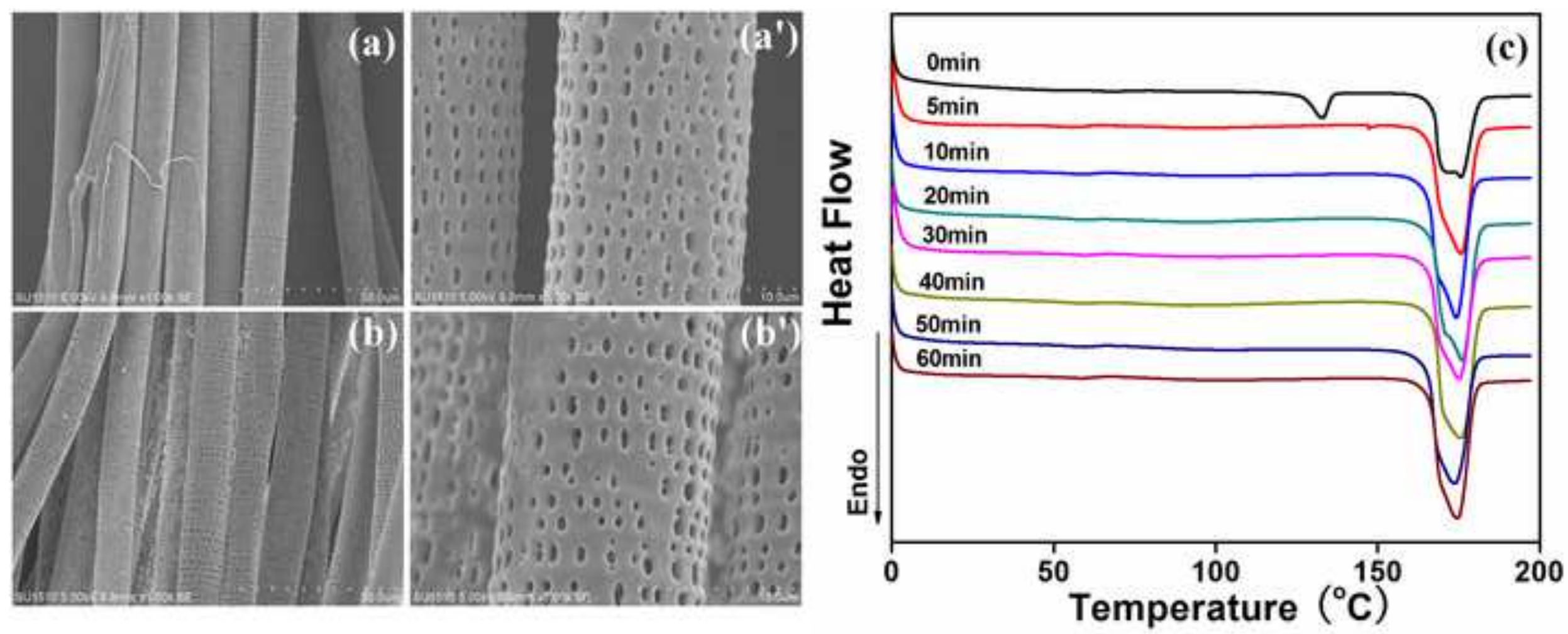

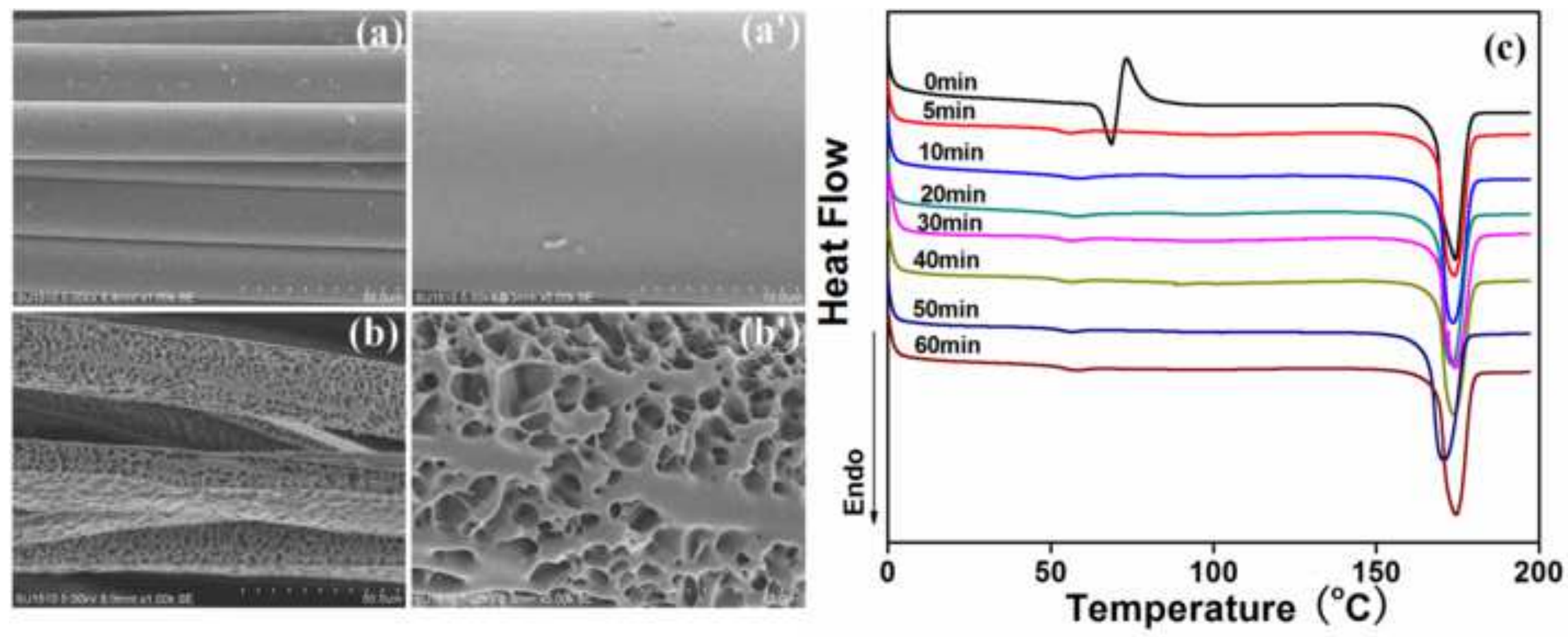


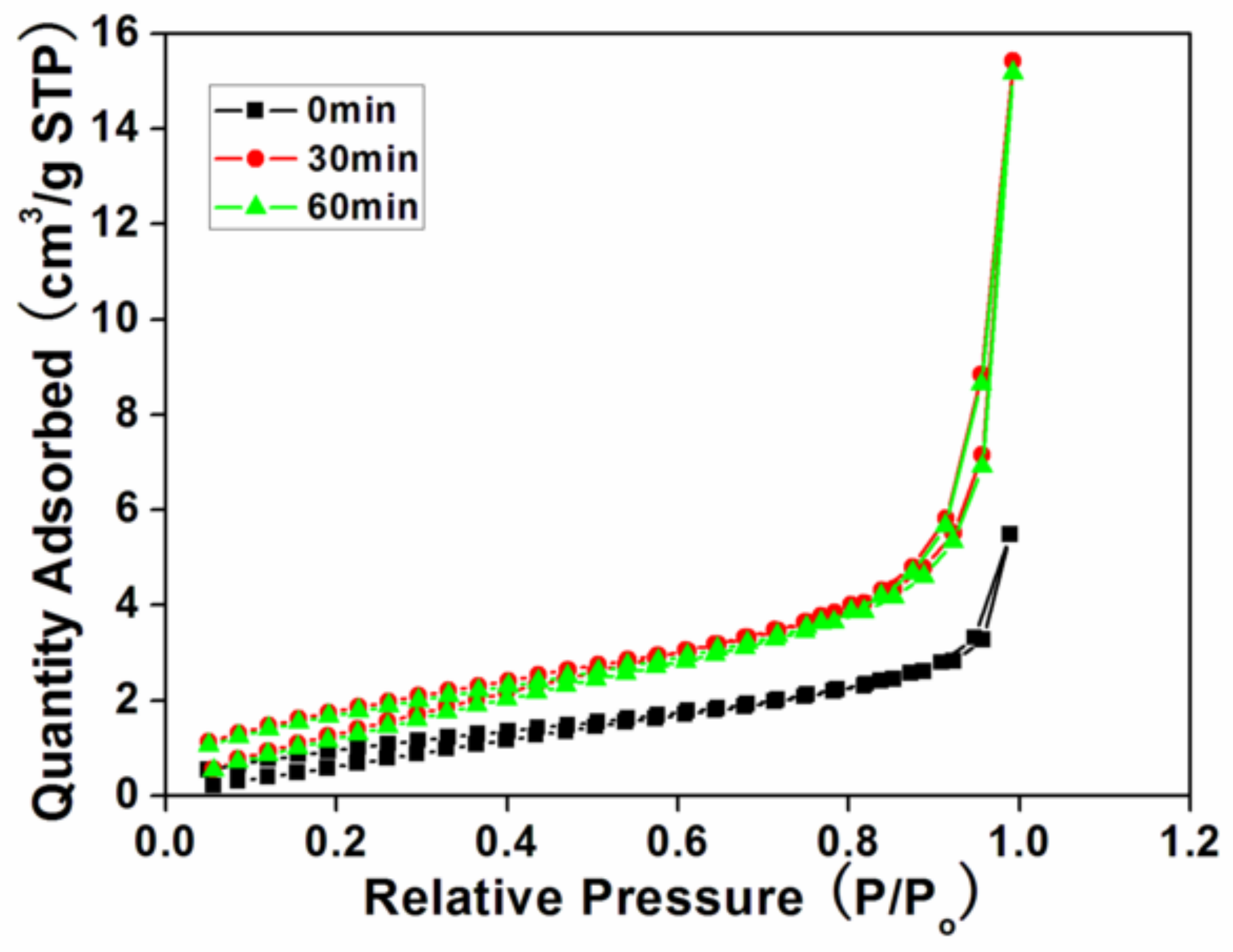



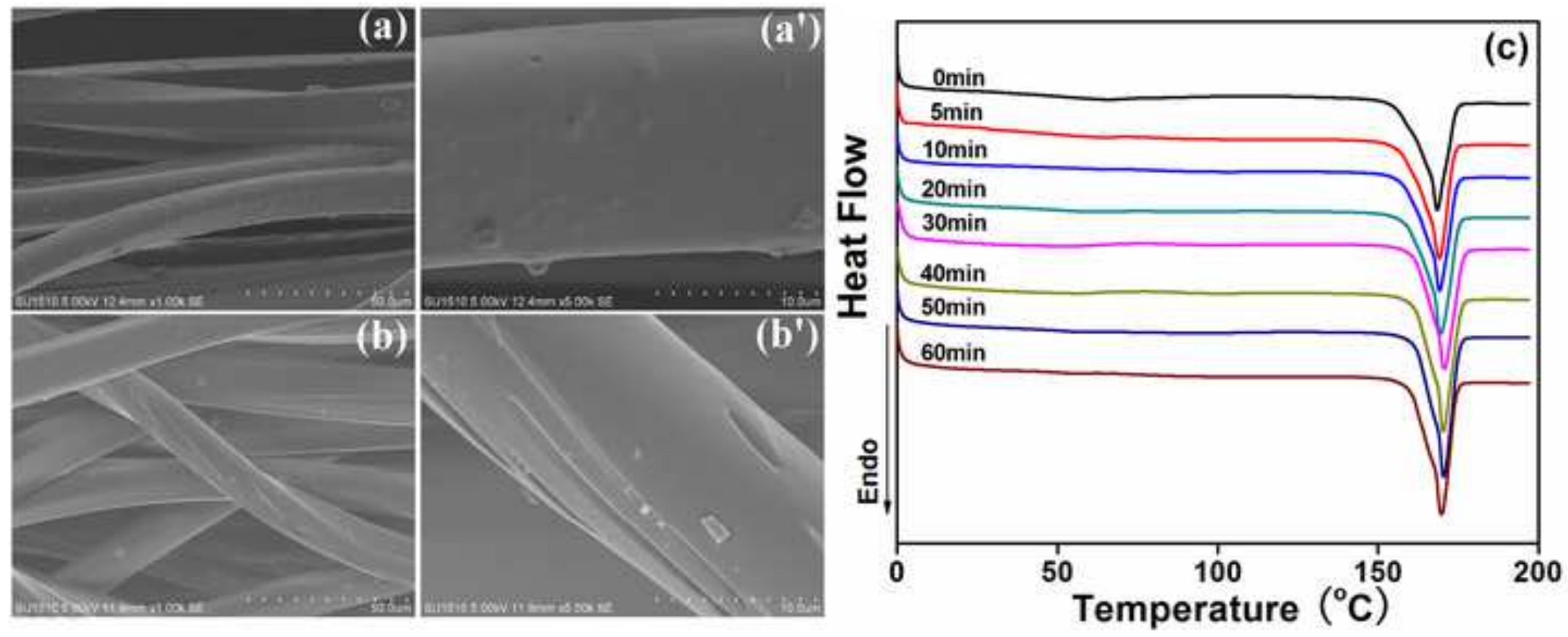

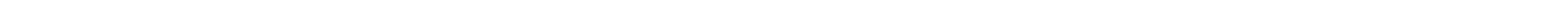

\section{Original CSF}

\section{列}

Graphica Abstract Image
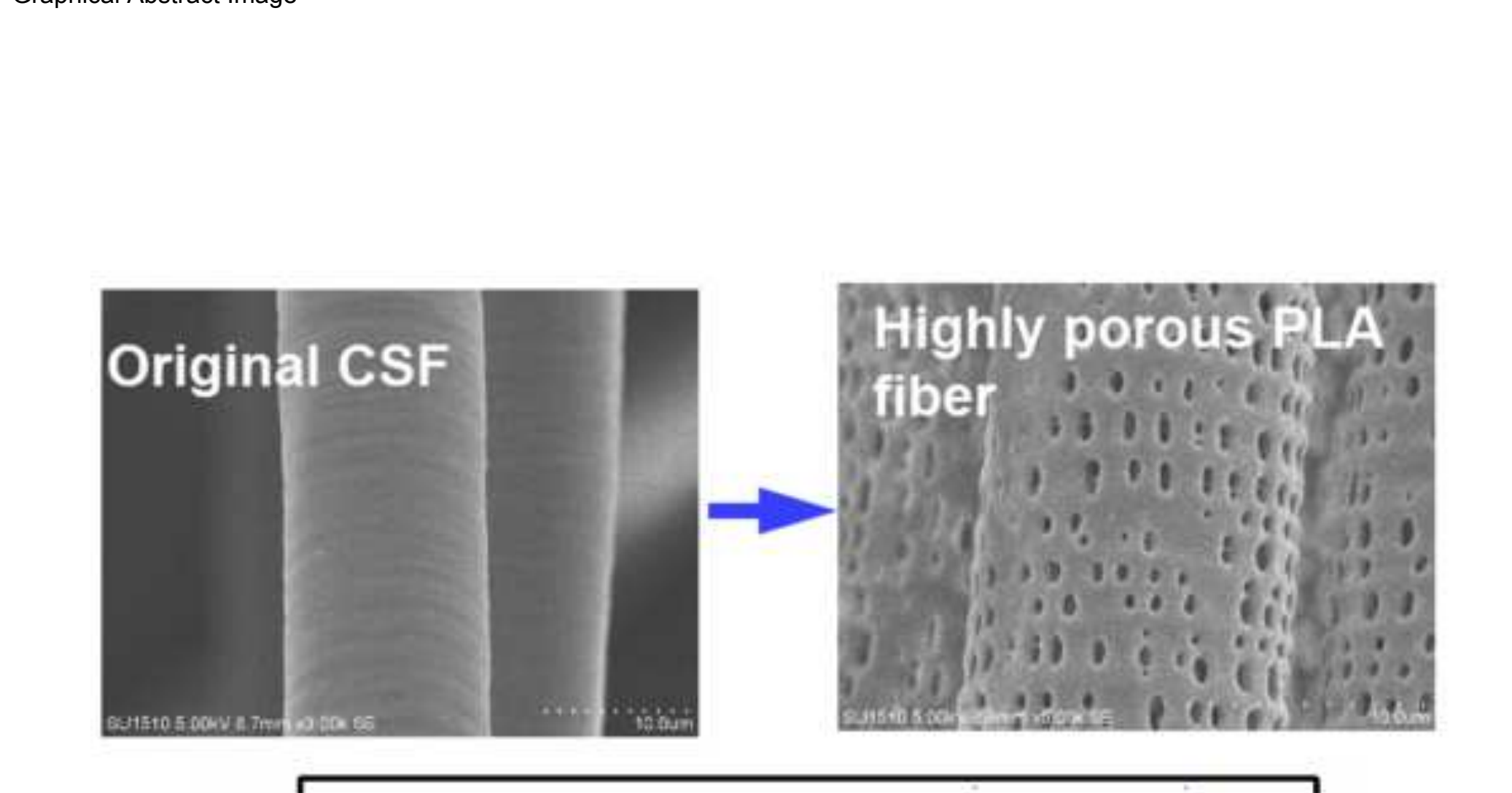


\section{Supporting Information}

\section{A Facile Method of Preparing Highly Porous Polylactide Microfibers}

Qingsheng Liu ${ }^{1,2 *}$, Qibing Yang ${ }^{1}$, Yuqi Zhou ${ }^{1}$, Mingming Zhao ${ }^{1}$, Ying Shen ${ }^{1}$, Fenglei

$$
\text { Zhou }^{2,3} \text {, R Hugh Gong }{ }^{2} \text {, Bingyao Deng }{ }^{1 *}
$$

${ }^{1}$ Key Laboratory of Eco-Textiles, Ministry of Education, Jiangnan University, Wuxi 214122, China

${ }^{2}$ The School of Materials, The University of Manchester, Manchester M13 9PL, United Kingdom

${ }^{3}$ Center for Imaging Sciences, The University of Manchester, Manchester M13 9PL, United Kingdom
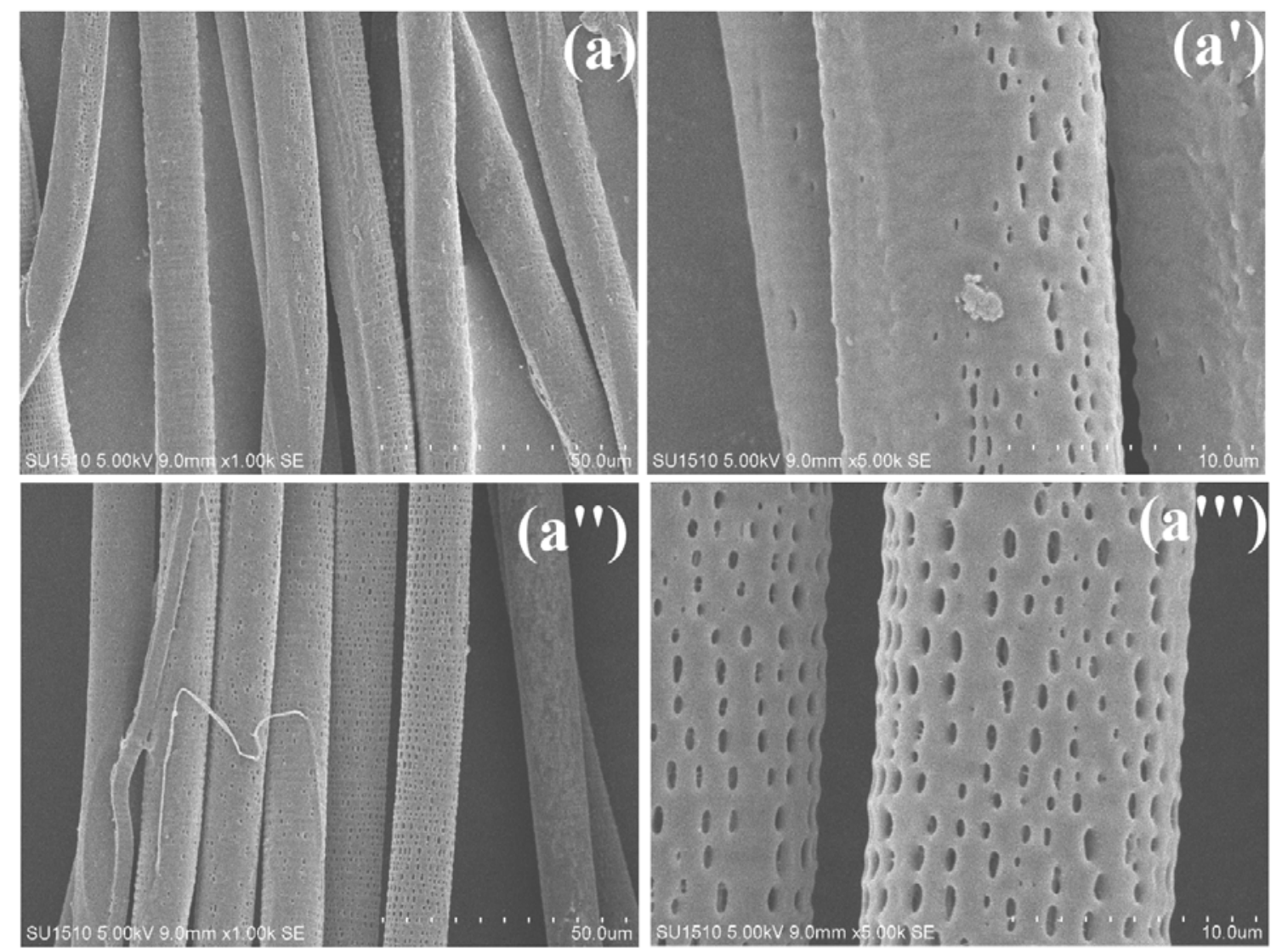

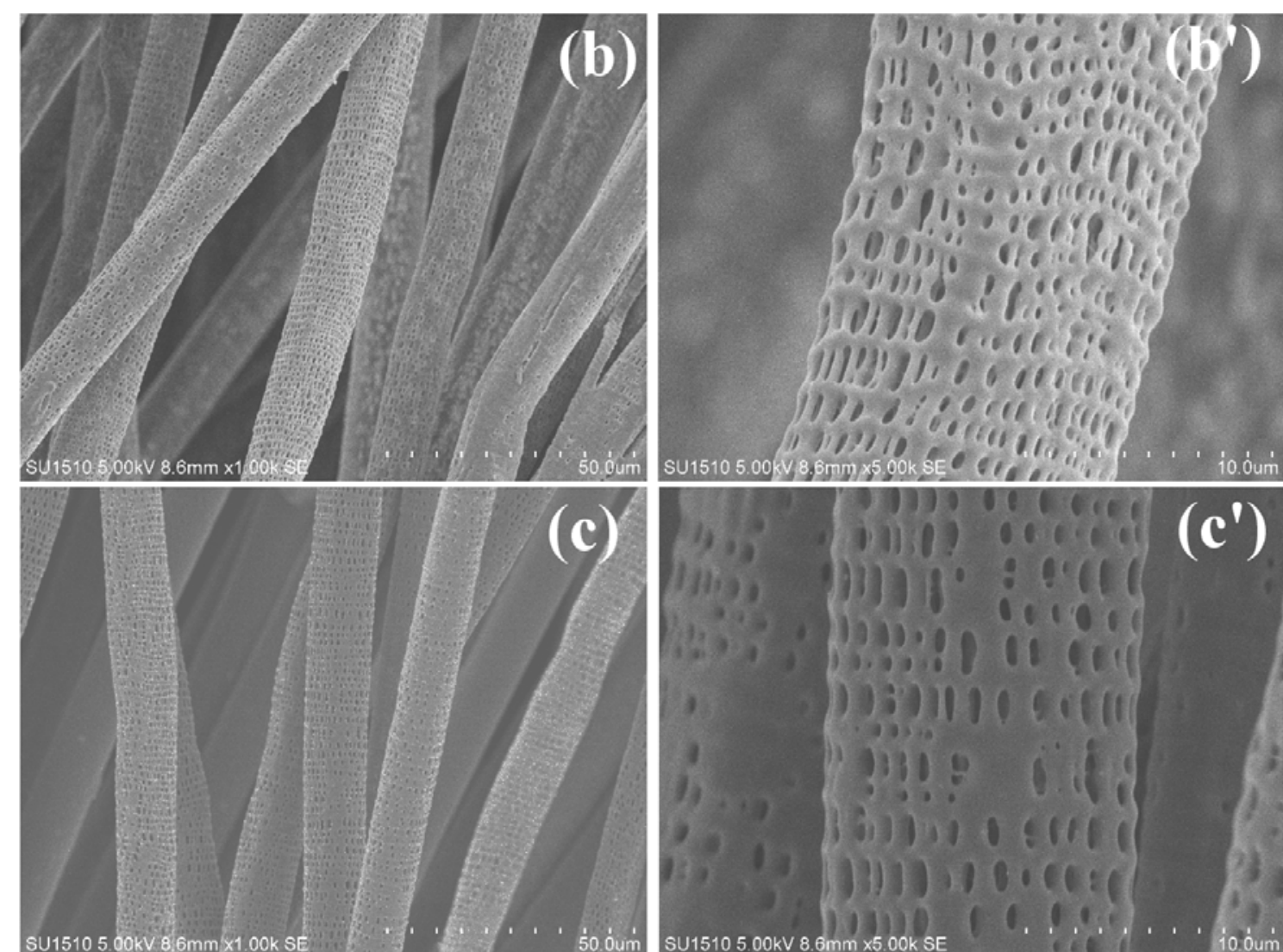

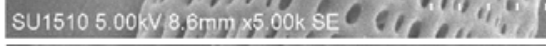
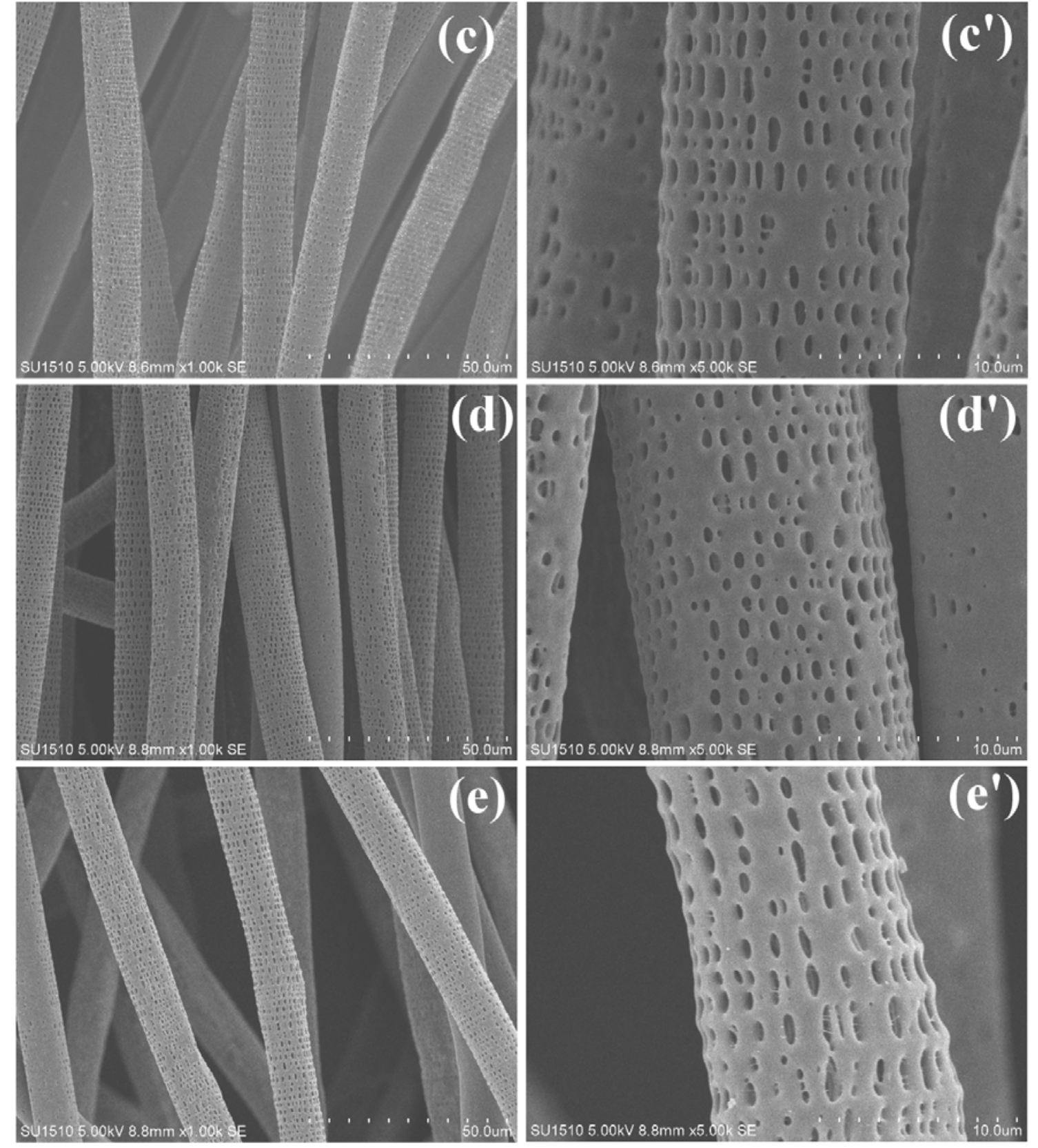

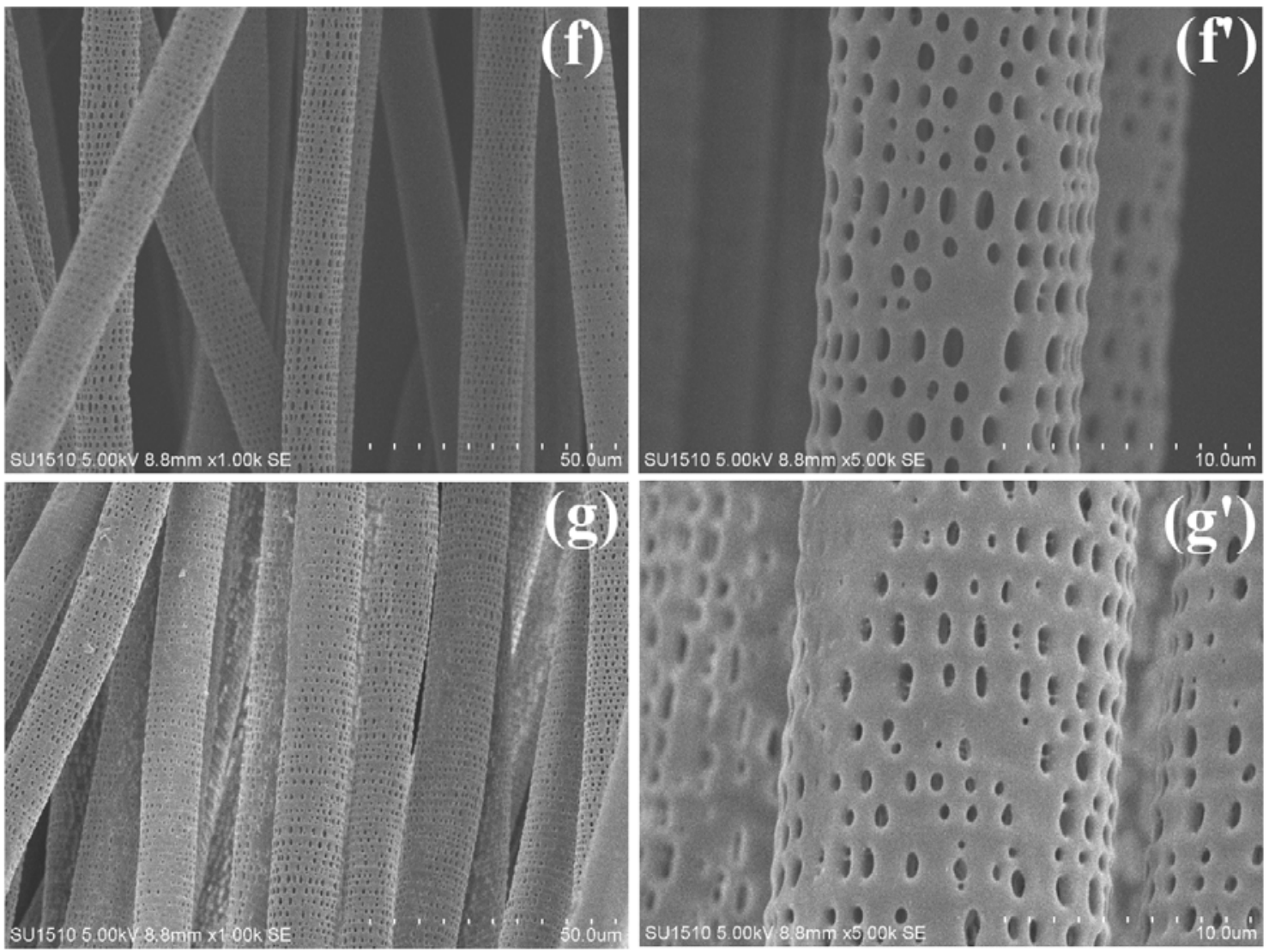

Figure S1 SEM photographs of surface morphology of CSF treated by ethyl acetate for 5min(a, a', a' and a','), 10min (b and b'), 20min (c and c'), 30min (d and d'), 40min (e and $\mathrm{e}^{\prime}$ ), 50min (f and f') and 60min (g and g'), respectively 


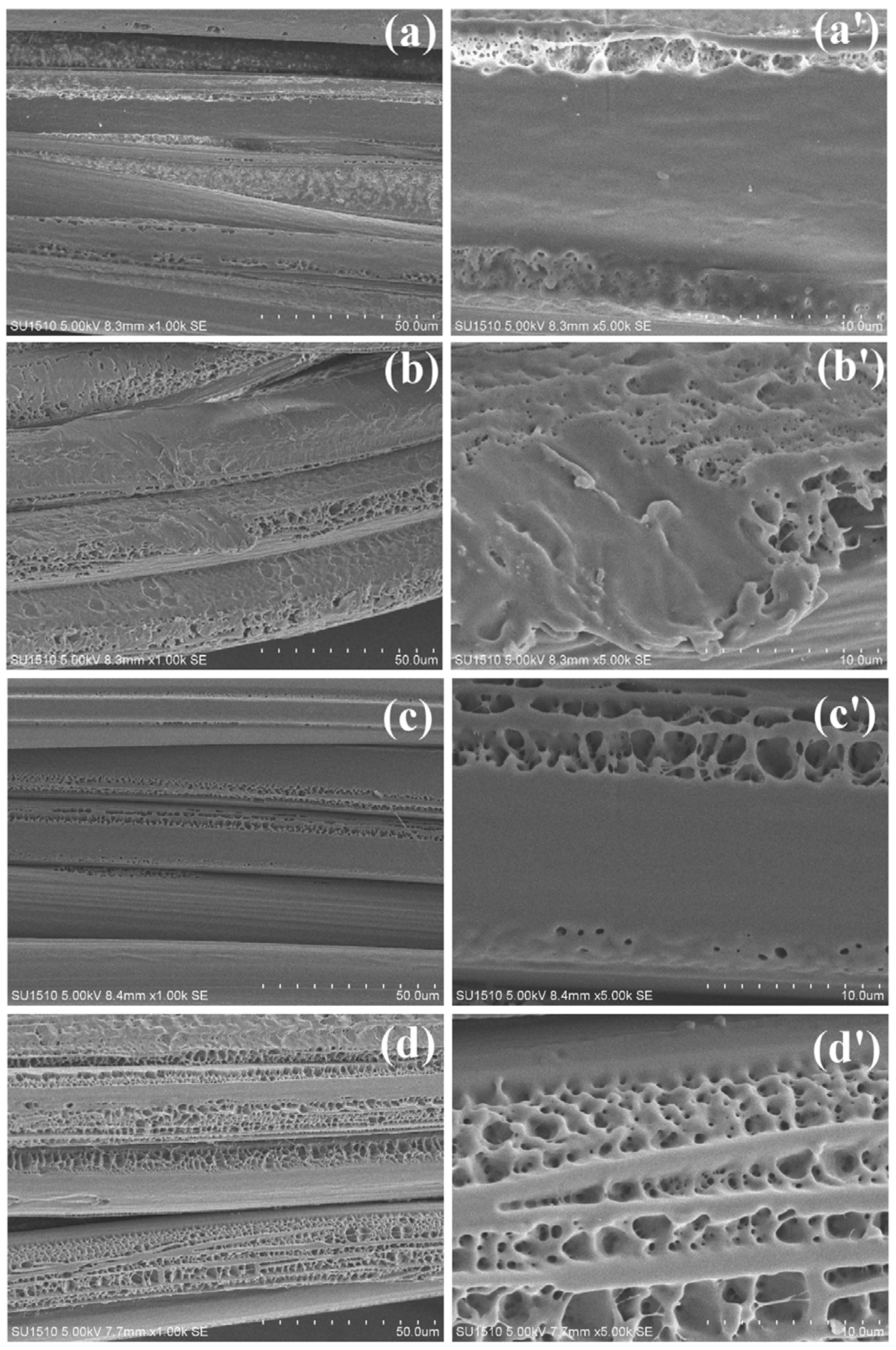



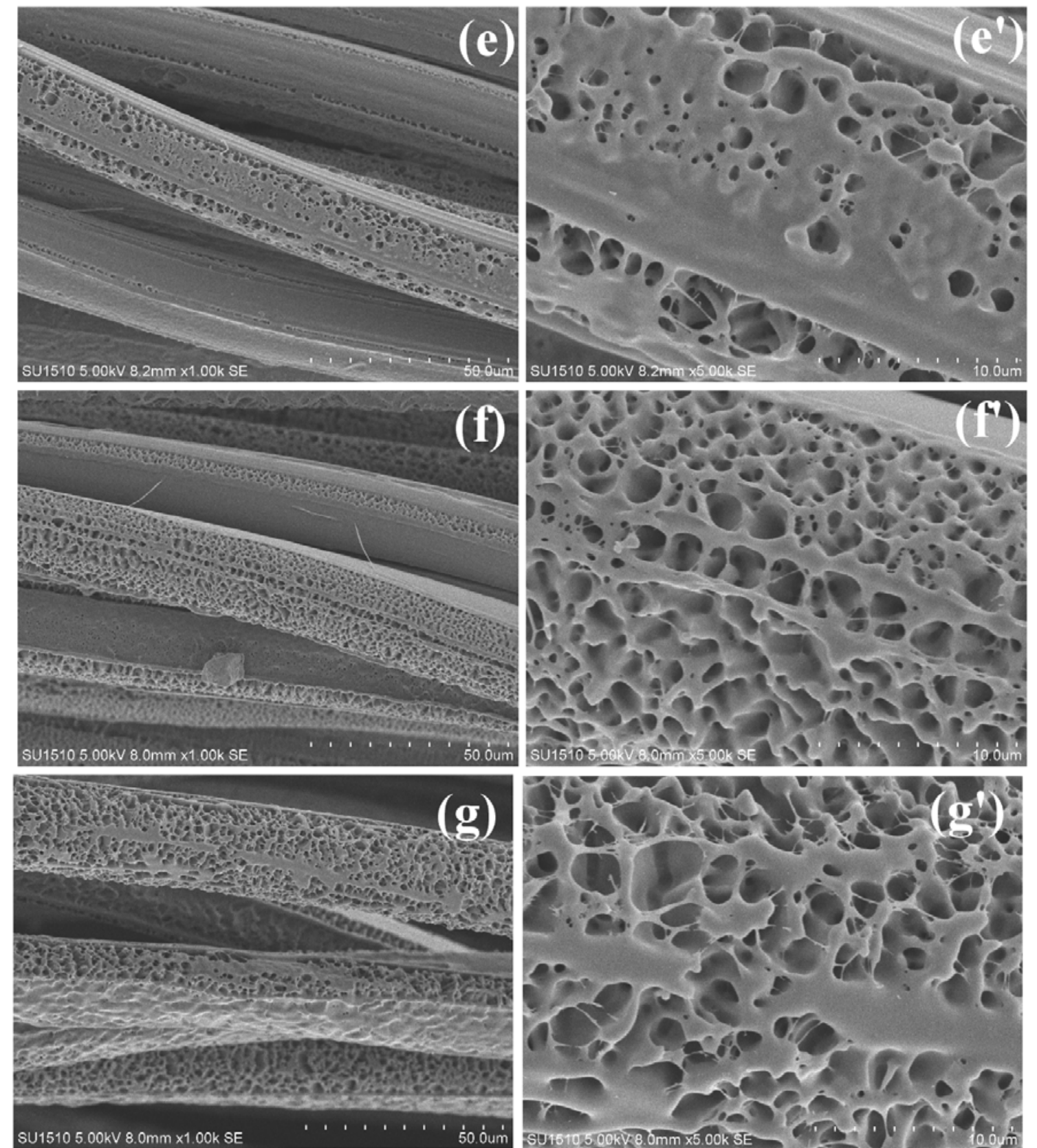

Figure S2 SEM photographs of surface morphology of POY treated by ethyl acetate for

5min(a and a'), 10min (b and b'), 20min (c and c'), 30min (d and d'), 40min (e and e'),

50min ( $\mathrm{f}$ and $\mathrm{f}^{\prime}$ ) and 60min (g and g'), respectively 